\title{
Testosterone and Cardiovascular Disease in Men
}

Emmanuela Quental Callou de Sa ${ }^{2}$, Francisco Carleial Feijó de Sá1, Augusto Saboia Neto ${ }^{1}$ and Juliana Viana Pinheiro

${ }^{1}$ Department of Internal Medicine, Universidade Federal do Cariri, Barbalha, Ceará, Brazil

${ }^{2}$ Coordinator, Department of Endocrinology, Universidade Federal do Cariri, Barbalha, Ceará, Brazil

*Corresponding author: Emmanuela Quental Callou de Sá, Universidade Federal do Cariri, Barbalha, Ceará, Brazil, Tel: 55-88-92017727; E-mail: eqcallou@gmail.com

Received date: July 20, 2014, Accepted date: August 17, 2014, Published date: August 24, 2014

Copyright:@ 2014 Callou de Sa, et al. This is an open-access article distributed under the terms of the Creative Commons Attribution License, which permits unrestricted use, distribution, and reproduction in any medium, provided the original author and source are credited.

\section{Key words}

Testosterone; Cardiovascular Disease; Coronary; Hormonal Therapy; Review Aging

\begin{abstract}
In this Century Cardiovascular Disease (CVD) is the most common isolated cause of death in developed countries. Many studies have suggested that men with low testosterone levels present higher incidence of components of metabolic syndrome and are at a greater risk of developing CVD.
\end{abstract}

Testosterone can affect the development of atherosclerosis in the coronary arteries. While this androgen seems to have a cardioprotective effect by benefiting endothelial function, inducing vasodilation, and reducing fat mass, insulin resistance and chronic inflammation, it also appears to increase endothelin, thromboxane $A 2$ and reactive oxygen species and renal smooth muscle cells.

The relation between testosterone and coronary disease in men has been the focus of study of many authors. Most studies point to a neutral and/or protective effect of endogenous testosterone in male cardiovascular health. Unfortunately, many intervention studies have not been able to confirm this effect with testosterone therapy.

More studies are needed to elucidate the pathogenic mechanisms of testosterone in cardiovascular health and to evaluate androgen receptor polymorphisms and their physiological responses to testosterone.

\section{Introduction}

In the beginning of the $20^{\text {th }}$ Century Cardiovascular Disease (CVD) was responsible for less than $10 \%$ of all deaths worldwide. In this century CVD has become the isolated leading cause of death in industrialized nations [1]. The male gender has traditionally been associated with a higher risk of CVD [2]. One explanation for this was elevated serum levels of testosterone known to be atherogenic.

Except for some indirect evidence, many studies have suggested that men with low levels of testosterone have higher incidence of the components of metabolic syndrome as well as a higher risk of developing CVD in their lifetime [2,3].

It is estimated ten percent of Myocardial Infarction (MI) patients do not have classic cardiovascular risk factors [4] and as a result new investigations for non-classic risk factors have emerged. Thus there has been a sharp increase in studies on the role of testosterone in the pathogenesis of ischemic cardiovascular disease.

This review summarizes the current evidence on the association between endogenous testosterone and CVD in men.

\section{Testosterone and Aging}

In men the most important serum androgen is testosterone, which is almost exclusively secreted by the testes. There it is produced more specifically by Leydig cells in response to the stimulus of a gonadotropin called Luteinizing Hormone (LH) [6].

In plasma, approximately $2 \%$ of testosterone travels freely, $44 \%$ are bound to Sex Hormone Binding Globulin (SHBG) and the remaining $54 \%$ are bound to albumin and other proteins. The portions that are free or bound to albumin are readily available to tissues and are called Bioavailable Testosterone (BT).

In men testosterone levels are highest after 30 years of age and start declining thereafter at about $1-2 \%$ every year [6]. There are different aspects to the changes in testosterone levels in age men: there are reduced testicular response to the gonadotropic stimuli associated with an unsatisfactory compensation by the hypothalamus-pituitary axis [7] and there is an aged-associated increase of SHBG levels by about $1.2 \%$ per year, so that the decrease Free Testosterone (FT) and BT serum levels is larger than that of Total Testosterone (TT) $[8,9]$.

As men age, this fall in the serum levels of testosterone intensifies: about one in every five men over the age of 60 and half of men over 80 have levels of testosterone below the lowest levels considered physiological in young men [8]. This relative deficiency is most commonly manifested with an increase in body fat and a reduction in both bone mass and muscle strength [8] contributing to the fat redistribution and to reduce in lean body mass [11,12]. Such loss in muscle mass at this age could explain the higher risk of falling, balance problems, obstructive sleep apnea, obesity, Diabetes Mellitus 2 (DM2), 
depression, chronic obstructive pulmonary disease, kidney and liver diseases and other functional limitations [13-15].

\section{Testosterone and Endothelial Dysfunction}

Endothelial dysfunction refers to an imbalance in the endothelial production of mediators that regulate vascular tonus, platelet aggregation, coagulation and fibrinolysis. It is frequently referred to as a worsening of the endothelium dependent relaxation caused by the bioavailability of nitric oxide (NO) and other vasodilating substances. Thus it can be found in many metabolic and/or cardiovascular diseases.

Testosterone is a vasoactive hormone with a predominantly vasodilating role in many vascular beds [16]. This androgen can exert its effects over the cardiovascular system through genomic models, by activating the androgen receptor (AR), and through non-genomic models, by activating the steroid receptors in the plasma membrane, which can also lead to blockage of the calcium L channels and opening of the calcium activated potassium channels [17]. The acute and chronic administration of testosterone has shown beneficial effects in ischemic myocardium induced by exercise in men with coronary arterial disease (CAD) $[18,19]$.

The immunosuppressant effect of androgens has been well understood and greater levels of auto-immune diseases in women and hypogonadic men are thought to be due to a down regulation of proinflammatory cytokines caused by testosterone [20]. Testosterone is capable of stimulating the production of an anti-inflammatory cytokine called interleukin 10 (IL-10) [21] and reducing other proinflammatory cytokines such as tumor necrosis factor a (TNFa), interleukin 1(IL-1) and interleukin $6 \beta[22,23]$ commonly elevated in elderly patients in subclinical inflammatory states [25].

A recent study of orchidectomized mice by Freeman et al. observed that androgenic supplementation was associated with a decline in inflammatory markers; while sub physiological testosterone levels were associated with an elevation of these markers, suggesting that the modulation of these hormonally responsive pathways could contribute to the development of the vascular pathogenesis [34].

In the last few years chronic inflammation has emerged as an important independent predictor of CAD. C-reactive Protein (CRP) is the most well studied inflammatory biomarker and today it is the most important among all the available ones, functioning as an independent risk factor for MI, stroke, peripheral vascular disease and sudden death [26]. Kupelian et al. [27], in a population based observational study of a sectional cohort with 1559 men with urologic symptoms, found an inverse association between testosterone and CRP, providing evidence to support testosterone's role in the inflammatory process. Finally, Wickramatilake et al. [28] demonstrated, in a case-control study of 206 men with CAD submitted to coronary angiography, that CVD patients had lower levels of testosterone and higher levels of CRP compared to the control group's. While CRP did show a positive association with the degree of atherosclerosis, testosterone did not. Inversely, in a similar study of 400 healthy men by Nakhai-Pour et al. [29], levels of TT and BT were not statistically associated to CRP in spite adjusting for age.

Testosterone also affects endothelial function by modulating the release of NO. This promotes vasodilation, inhibits platelet aggregation and adhesion of leukocytes to the endothelium, migration and growth of smooth muscle cells and oxidation of LDL-cholesterol
(LDL-c). In a study using endothelial cell culture, Campelo et al. [30] demonstrated that testosterone increases the production of $\mathrm{NO}$ via AR.

Finally, testosterone also has vasoconstrictor effects. The administration of $200 \mathrm{mg}$ of testosterone cypionate to healthy men in a double-blind, randomised, placebo-controlled trial revealed increased platelet aggregation by modulating the expression of thromboxane A2 receptors [31]. In another study, testosterone was implicated for impairing coronary vasodilation in response to adenosine in isolated mice heart models [32]. Such effect was attributed to and acutely mediated by the release of thromboxane, which is a potent vasoconstrictor and platelet aggregate.

Endothelins are potent endogenous vasoconstricting peptides. The relation between testosterone and endothelin 1 (ET-1) is complex with some studies suggesting that testosterone increases levels of ET-, mediating vasoconstriction, while others suggest that the levels of these peptides are higher in hypogonadism situations [33].

Recently Chignalia et al. [34] proposed that testosterone induces the generation of Reactive Oxygen Species (ROS) in renal smooth muscle cells. Since ROS in the kidneys reduce the bioavailability of $\mathrm{NO}$ and increases vasoconstriction [35], it is possible that this androgen can contribute to the loss in renal function and vascular dysfunction via ROS production.

As discussed so far, testosterone modulates the mechanisms associated with endothelial dysfunction that occurs during old age. Although testosterone levels are associated with endothelial dysfunction and increased CVD, this relation of cause and effect still remains controversial. Some authors advocate that reduced levels of testosterone could function as a old age marker, and such reduction corresponding only to an epiphenomenon [36]. In reality, elevated levels of this androgen in the elderly reflect good health and a reduced risk for cardiovascular events [37].

\section{Testosterone and Cardiovascular Risk Factors}

Low levels of endogenous testosterone have been associated with the presence of many components of metabolic syndrome, including dyslipidemia, visceral obesity, Systemic Arterial Hypertension (SAH), DM2, hepatic steatosis, and others [18,38-40].

Important meta-analysis and prospective studies have demonstrated a negative association between testosterone and the incidence of Diabetes Mellitus in men [41-43]. However the temporal nature of this association is still controversial, with some arguments in each direction. Some have suggested that diabetes mellitus in mice cause a reduction in the number of Leydig cells [44] resulting in lower levels of testosterone, while other authors have put forth that elevated levels of this androgen increase lean mass and reduce the levels of TNF- $\alpha$ and insulin resistance [41-43].

Morbidly obese patients with peripheral insulin resistance frequently have low levels of TT, which increase with weight loss. The mechanisms responsible for the reduction in the levels of testosterone in obese men are not fully understood. The reduction in FT in severe obesity is not associated to an increase in LH suggesting a form of hypogonadotropic hypogonadism. One postulated hypothesis would be a dysfunction in the testicular hypothalamic-pituitary axis characterized by the reduction of peaks of LH [45]. Another suggested mechanism would be an increase in the peripheral conversion of androgens into estrogens by the enzyme aromatase, which is present in 
elevated concentrations in adipose tissue [45]. Furthermore, obesity is one of many conditions that can result in low levels of SHBG, with insulin being an important inhibitor of the production of this globulin in the liver [45]. This way, individuals with insulin resistance tend to present with lower values of TT.

Through the activation of $\beta$-adrenergic AR expressed in adipose cells, androgens stimulate hormone sensitive lipase and inhibit the activity of lipoproteic lipase, the main enzyme that regulates the intake of glucose in adipose tissues [46]. As a result testosterone is able to reduce the fat reserves in adipose tissue by stimulating lipolysis. This explains the increase in body fat mass associated with low levels of testosterone observed in hypogonadism patients.

Some interventionist prospective studies have revealed beneficiary effects of testosterone therapy in the parameters for metabolic syndrome. Kalinchenko et al. [47], in a study with 184 men with metabolic syndrome and low levels of testosterone, demonstrated that treatment for 30 weeks with Intramuscular (IM) testosterone undecanoate reduced Body Mass Index (BMI), Waist Circumference (WC), insulin levels, CRP, IL-1 $\beta$ and TNF- $\alpha$ in comparison with placebo but there was no significant change in levels of glucose, IL-6 and IL-10 and in lipid profile. In another prospective, longitudinal study by Yassin et al. [48] of 261 men, treatment with IM testosterone undecanoate during five years reduced WC, BMI, cholesterol, LDL-c, triglycerides, fasting glucose, glycated hemoglobin and arterial pressure (AP) but did not produce an increase in HDL-cholesterol (HDL-c) .

Haddad et al. [49] in a meta-analysis of 30 randomised placebocontrolled studies, with 1642 men, 808 of which treated with testosterone in the commercially available forms (IM, transdermical, oral and buccal) showed negligible effects of testosterone on the levels of lipids, AP, glicemic control and cardiovascular events.

Finally, Kelly et al. [50] in a study with orchidectomized mice, with androgen receptor deficiency and with a cholesterol rich diet, observed the effect of testosterone therapy over regulatory enzymes in the synthesis of fatty acids. In the testosterone supplementation group there were smaller fat deposits in hepatocytes when compared to placebo. Such result suggests a different mechanism of action of testosterone, independent of $\mathrm{AR}$, over the regulation of the main lipogenic enzymes and protection against hepatic steatosis.

\section{Testosterone and Cardiovascular Disease}

Atherosclerosis is a complex pathology characterized by endothelial dysfunction, vascular inflammation and lipid buildup in the intima layer of blood vessels. The development of atherosclerosis is promoted not only by systemic factors, but also metabolic, vascular and inflammatory dysfunctions of the vessels' walls.

Testosterone can affect the development of atherosclerosis in coronary arteries. While it seems to have cardioprotective effects by benefiting endothelial function, inducing vasodilation and reducing insulin resistance and chronic inflammation [40,51,52], it also appears to increase endothelin, thromboxane A2 and ROS in renal smooth muscle cells $[31,32,34,35]$.

The relationship between testosterone and CAD in men has been the focus of study of many authors. Most of the studies point to a neutral and/or protective effect of endogenous testosterone in cardiovascular health.
In this line of research, Callou de Sá et al.[53], in a case-control study of 144 patients who underwent elective coronary angiography found a neutral effect of TT, BT, FT and free androgen index in the prevalence of CAD. Similarly, Vikan et al. [52] in a study with 1318 men followed for 9.1 years, did not find an association between TT and FT and the incidence of MI. Araujo et al. [55] in a meta-analysis with 11831 participants did not find a statistically significant correlation between reduced levels of testosterone and cardiovascular mortality either.

On the other hand, Hyde et al.[56]in a population based prospective study of 3637 elderly men followed by 5.1 years, found that reduced FT levels were associated with higher mortality by CVD. Furthermore, Li Li et al.[56], in a study of 803 patients who underwent elective coronary angiography, demonstrated reduced levels of TT to be associated with CAD and with it's severity determined by the Gensini score.

Despite the beneficial effects of endogenous testosterone in men's cardiovascular health well described in the literature, a number of studies were not able to replicate these beneficial effects with testosterone therapy. In fact, when observed studies involving interventions with testosterone therapy and CVD, results vary greatly between authors.

In the TOM study [57], elderly participants with limited mobility and low levels of testosterone were randomly assigned to either a placebo group or a therapy group receiving transdermic gel with 100 $\mathrm{mg}$ of testosterone during six months. It had to be discontinued prematurely due to a higher incidence of cardiovascular events in the testosterone group. Similarly, $\mathrm{Xu}$ et al.[58] in a meta-analysis of 27 randomised placebo-controlled trials, with 2994 participants, 1733 of which used testosterone, found RR 1.54 for cardiovascular events $(95 \%$ CI,1.09 to 2.18) for the testosterone group. In accordance with these results Vigen et al. [59] in a retrospective cohort study of 8709 men with low levels of testosterone who underwent coronary angiography, of which 1223 received testosterone therapy, showed increased mortality, MI and stroke rates in the testosterone group.

Haddad et al.[49] in a previously cited meta-analysis showed only negligible effects of testosterone in cardiovascular events OR 1.86 (95\% CI, 0.78 to 4.23 ). Similarly Fernandez-Balsells et al. [60], in a metaanalysis of 51 studies with 2716 men who used testosterone did not find a significant difference in mortality by all causes, arrhythmias, coronary bypass surgery or MI between the testosterone group and the control group.

On the other hand, Toma et al.[61], in a meta-analysis of randomised controlled trials of 198 men with heart failure, found testosterone therapy was associated with a significant improvement in exercise capacity compared with placebo (New York Heart Association functional class improved by $\geq 1$ grade, increase in the 6-minute walk test and the peak oxygen consumption in exercise).

Finally, many authors agree that low testosterone levels could be interpreted as a factor, which when associated with old age contributes to an increase in comorbidities [51], or could help reveal previously existing hidden pathologies $[16,39,51]$ functioning as a biomarker for old age $[16,51]$. High levels of this androgen in the elderly reflect good health and a reduced risk of cardiovascular events $[16,51]$. 


\section{Conclusion}

Endogenous testosterone exerts a neutral and/or beneficial effect in the male cardiovascular system. This androgen favors vasodilation, has a pro and anti-aggregate role, and reduces the fat mass, inflammatory biomarkers, insulin resistance and the incidence of diabetes mellitus. Lending support to this line of thought, some observational studies point to a larger prevalence of cardiovascular disease and cardiovascular mortality in populations with reduced serum levels of this hormone. On the other hand, interventional studies in which testosterone replacement was used do not reach a uniform consensus with regards to the cardiovascular endpoints, with some suggesting higher risk, some neutral and others describing lower risk. It is important to keep in mind that this study describes the cardiovascular effects of testosterone replacement therapy and does not investigate improvements in the quality of life of the patients. Testosterone replacement therapy in men with hypogonadism by pituitary or testicular diseases deserves special consideration. More studies are needed to try to describe the pathogenic mechanisms of testosterone in cardiovascular health and to investigate polymorphisms of the androgen receptor in the physiological response to it.

\section{References}

1. WHO - World Health Organization (1998) Life in the 21st century: A vision for all. The world health report.

2. Arnlöv J, Pencina MJ, Amin S, Nam BH, Benjamin EJ, et al. (2006) Endogenous sex hormones and cardiovascular disease incidence in men. Ann Intern Med 145: 176-184.

3. Turhan S, Tulunay C, Güleç S, Ozdöl C, Kilickap M, et al. (2007) The association between androgen levels and premature coronary artery disease in men. Coron Artery Dis 18: 159-162.

4. Yusuf S, Hawken S, Ounpuu S, Dans T, Avezum A, et al. (2004) Effect of potentially modifiable risk factors associated with myocardial infarction in 52 countries (the INTERHEART study): case-control study. Lancet 364: 937-952.

5. Gebara OC, Vieira NW, Meyer JW, Calich AL, Tai EJ, et al. (2002) [Cardiovascular effects of testosterone]. Arq Bras Cardiol 79: 644-649.

6. Feldman HA, Longcope C, Derby CA, Johannes CB, Araujo AB, et al. (2002) Age trends in the level of serum testosterone and other hormones in middle-aged men: longitudinal results from the Massachusetts male aging study. J Clin Endocrinol Metab 87: 589-598.

7. Kaufman JM, Vermeulen A (2005) The decline of androgen levels in elderly men and its clinical and therapeutic implications. Endocr Rev 26: 833-876.

8. Muller M, den Tonkelaar I, Thijssen JH, Grobbee DE, van der Schouw YT (2003) Endogenous sex hormones in men aged 40-80 years. Eur J Endocrinol 149: 583-589.

9. Feldman HA, Longcope C, Derby CA, Johannes CB, Araujo AB, et al. (2002) Age trends in the level of serum testosterone and other hormones in middle-aged men: longitudinal results from the Massachusetts male aging study. J Clin Endocrinol Metab 87: 589-598.

10. Harman SM, Metter EJ, Tobin JD, Pearson J, Blackman MR (2001) Longi- tudinal effects of aging on serum total and free testosterone levels in healthy men. Baltimore Longitudinal Study of Aging. J Clin Endocrinol Metab 86:724-731.

11. Dunajska K, Milewicz A, Szymczak J, Jêdrzejuk D, Kuliczkowski W, et al. (2004) Evaluation of sex hormone levels and some metabolic factors in men with coronary atherosclerosis. Aging Male 7: 197-204.

12. Iannuzzi-Sucich M, Prestwood KM, Kenny AM (2002) Prevalence of sarcopenia and predictors of skeletal muscle mass in healthy, older men and women. J Gerontol A Biol Sci Med Sci 57: 772-777.

13. Simon D, Charles MA, Nahoul K, Orssaud G, Kremski J, et al. (1997) Association between plasma total testosterone and cardiovascular risk factors in healthy adult men: The Telecom Study. J Clin Endocrinol Metab 82: 682-685.

14. Khaw KT, Dowsett M, Folkerd E, Bingham S, Wareham N, et al. (2007) Endogenous testosterone and mortality due to all causes, cardiovascular disease, and cancer in men: European prospective investigation into cancer in Norfolk (EPIC-Norfolk) Prospective Population Study. Circulation 116: 2694-2701.

15. Shores MM, Matsumoto AM, Sloan KL, Kivlahan DR (2006) Low serum testosterone and mortality in male veterans. Arch Intern Med 166: 1660-1665.

16. Kelly DM, Jones TH (2013) Testosterone: a vascular hormone in health and disease. J Endocrinol 217: R47-71.

17. Webb CM, McNeill JG, Hayward CS, de Zeigler D, Collins P (1999) Effects of testosterone on coronary vasomotor regulation in men with coronary heart disease. Circulation 100: 1690-1696.

18. Wu J, Hadoke PW2, Mair I2, Lim WG2, Miller E2, et al. (2014) Modulation of neointimal lesion formation by endogenous androgens is independent of vascular androgen receptor. Cardiovasc Res 103: 281-290.

19. English KM, Steeds RP, Jones TH,Diver MJ, Channer KS (2000) Lowdose transdermal testosterone therapy improves angina threshold in men with chronic stable angina: A randomized, double-blind, placebocontrolled study. Circulation 102:1906-1911

20. Bain J (2007) The many faces of testosterone. Clin Interv Aging 2: 567-576.

21. Liva SM, Voskuhl RR (2001) Testosterone acts directly on CD4+ T lymphocytes to increase IL-10 production. J Immunol 167: 2060-2067.

22. Malkin CJ, Pugh PJ, Jones RD, Kapoor D, Channer KS, et al. (2004) The effect of testosterone replacement on endogenous inflammatory cytokines and lipid profiles in hypogonadal men. J Clin Endocrinol Metab 89: 3313-3318.

23. Saad F, Aversa A, Isidori AM, Zafalon L, Zitzmann M, et al. (2011) Onset of effects of testosterone treatment and time span until maximum effects are achieved. Eur J Endocrinol 165: 675-685.

24. Singh $T$, Newman $A B$ (2011) Inflammatory markers in population studies of aging. Ageing Res Rev 10: 319-329.

25. Freeman BM, Mountain DJ, Brock TC, Chapman JR, Kirkpatrick SS, et al. (2014) Low testosterone elevates interleukin family cytokines in a rodent model: a possible mechanism for the potentiation of vascular disease in androgen-deficient males. J Surg Res 190:319-27.

26. Silva D, Pais de Lacerda A (2012) [High-sensitivity C-reactive protein as a biomarker of risk in coronary artery disease]. Rev Port Cardiol 31: 733-745.

27. Kupelian V, Chiu GR, Araujo AB, Williams RE, Clark RV, et al. (2010) Association of sex hormones and C-reactive protein levels in men. Clin Endocrinol (Oxf) 72: 527-533.

28. Wickramatilake CM, Mohideen MR, Withanawasam BP, Pathirana C (2014) Testosterone and high-sensitive C-reactive protein in coronary artery disease patients awaiting coronary artery bypass graft. Andrologia .

29. Nakhai Pour HR, Grobbee DE, Muller M, van der Schouw YT (2007) Association of endogenous sex hormone with C-reactive protein levels in middle-aged and elderly men. Clin Endocrinol (Oxf) 66: 394-398.

30. Campelo AE, Cutini PH, Massheimer VL (2012) Testosterone modulates platelet aggregation and endothelial cell growth through nitric oxide pathway. J Endocrinol 213: 77-87.

31. Ajayi AA, Mathur R, Halushka PV (1995) Testosterone increases human platelet thromboxane $\mathrm{A} 2$ receptor density and aggregation responses. Circulation 91: 2742-2747.

32. Ceballos G, Figueroa L, Rubio I, Gallo G, Garcia A, et al. (1999) Acute and nongenomic effects of testosterone on isolated and perfused rat heart. J Cardiovasc Pharmacol 33: 691-697.

33. Tostes RC, Fortes ZB, Callera GE, Montezano AC, Touyz RM, et al. (2008) Endothelin, sex and hypertension. Clin Sci (Lond) 114: 85-97.

34. Chignalia AZ, Schuldt EZ, Camargo LL, Montezano AC, Callera GE, et al. (2012) Testosterone induces vascular smooth muscle cell migration by 
NADPH oxidase and c-Src-dependent pathways. Hypertension 59: 1263-1271.

35. Lopes RA, Neves KB, Carneiro FS, Tostes RC (2012) Testosterone and vascular function in aging. Front Physiol 3: 89.

36. Horstman AM, Dillon EL, Urban RJ, Sheffield-Moore M (2012) The role of androgens and estrogens on healthy aging and longevity. J Gerontol A Biol Sci Med Sci 67: 1140-1152.

37. Sá EQ, Sá FC, Guedes AD, Verreschi IT (2009) [Serum testosterone and cardiovascular disease in men]. Arq Bras Endocrinol Metabol 53: 915-922.

38. Oskui PM, French WJ, Herring MJ, Mayeda GS, Burstein S, et al. (2013) Testosterone and the cardiovascular system: a comprehensive review of the clinical literature. J Am Heart Assoc 2: e000272.

39. Hackett G, Kirby M2, Sinclair AJ3 (2014) Testosterone deficiency, cardiac health, and older men. Int J Endocrinol 2014: 143763.

40. Corona G, Monami M, Rastrelli G, Aversa A, Sforza A, et al. (2011) Type 2 diabetes mellitus and testosterone: a meta-analysis study. Int J Androl 34: 528-540.

41. Ding EL, Song Y, Malik VS, Liu S (2006) Sex differences of endogenous sex hormones and risk of type 2 diabetes: a systematic review and metaanalysis. JAMA 295: 1288-1299.

42. Colangelo LA, Ouyang P, Liu K, Kopp P, Golden SH, et al. (2009) Association of endogenous sex hormones with diabetes and impaired fasting glucose in men: multi-ethnic study of atherosclerosis. Diabetes Care 32: 1049-1051.

43. Pitteloud N, Hardin M, Dwyer AA, Valassi E, Yialamas M, et al. (2005) Increasing insulin resistance is associated with a decrease in Leydig cell testosterone secretion in men. J Clin Endocrinol Metab 90: 2636-2641.

44. Vermeulen A (1996) Decreased androgen levels and obesity in men. Ann Med 28: 13-15.

45. Mårin P, Odén B, Björntorp P (1995) Assimilation and mobilization of triglycerides in subcutaneous abdominal and femoral adipose tissue in vivo in men: effects of androgens. J Clin Endocrinol Metab 80: 239-243.

46. Kalinchenko SY, Tishova YA, Mskhalaya GJ, Gooren LJ, Giltay EJ, et al. (2010) Effects of testosterone supplementation on markers of the metabolic syndrome and inflammation in hypogonadal men with the metabolic syndrome: the double-blinded placebo-controlled Moscow study. Clin Endocrinol (Oxf) 73: 602-612.

47. Yassin DJ, Doros G, Hammerer PG, Yassin AA (2014) Long-term testosterone treatment in elderly men with hypogonadism and erectile dysfunction reduces obesity parameters and improves metabolic syndrome and health-related quality of life. J Sex Med 11:1567-1576.

48. Haddad RM, Kennedy CC, Caples SM, Tracz MJ, Boloña ER, et al. (2007) Testosterone and cardiovascular risk in men: a systematic review and meta-analysis of randomized placebo-controlled trials. Mayo Clin Proc 82:29-39.

49. Kelly DM, Nettleship JE2, Akhtar S2, Muraleedharan V3, Sellers DJ4, et al. (2014) Testosterone suppresses the expression of regulatory enzymes of fatty acid synthesis and protects against hepatic steatosis in cholesterol-fed androgen deficient mice. Life Sci 109: 95-103.

50. Yeap BB (2014) Sex steroids and cardiovascular disease. Asian J Androl 16: $239-247$

51. Li L, Guo CY, Jia EZ, Zhu TB, Wang LS, et al. (2012) Testosterone is negatively associated with the severity of coronary atherosclerosis in men. Asian J Androl 14: 875-878

52. Callou de Sá EQ, Feijó de Sá FC, e Silva Rde S, de Oliveira KC, Guedes $\mathrm{AD}$, et al. (2011) Endogenous oestradiol but not testosterone is related to coronary artery disease in men. Clin Endocrinol (Oxf) 75: 177-183.

53. Vikan T, Schirmer H, Njølstad I, Svartberg J (2009) Endogenous sex hormones and the prospective association with cardiovascular disease and mortality in men: the Tromsø Study. Eur J Endocrinol 161: 435-442.

54. Araujo AB, Dixon JM, Suarez EA, Murad MH, Guey LT, et al. (2011) Clinical review: Endogenous testosterone and mortality in men: a systematic review and meta-analysis. J Clin Endocrinol Metab 96: 3007-3019.

55. Hyde Z, Norman PE, Flicker L, Hankey GJ, Almeida OP, et al. (2012) Low free testosterone predicts mortality from cardiovascular disease but not other causes: the Health in Men Study. J Clin Endocrinol Metab 97: 179-189.

56. Basaria S, Coviello AD, Travison TG, Storer TW, Farwell WR, et al. (2010) Adverse events associated with testosterone administration. N Engl J Med 363: 109-122.

57. Xu L, Freeman G, Cowling BJ, Schooling CM (2013) Testosterone therapy and cardiovascular events among men: a systematic review and meta-analysis of placebo-controlled randomized trials. BMC Medicine 11:108-116.

58. Vigen R, O'Donnell CI, Barón AE, Grunwald GK, Maddox TM, et al. (2013) Association of testosterone therapy with mortality, myocardial infarction, and stroke in men with low testosterone levels. JAMA 310: 1829-1836.

59. Fernández-Balsells MM, Murad MH, Lane M, Lampropulos JF, Albuquerque F, et al. (2010) Clinical review 1: Adverse effects of testosterone therapy in adult men: a systematic review and meta-analysis. J Clin Endocrinol Metab 95: 2560-2575.

60. Toma M, McAlister FA, Coglianese EE, Vidi V, Vasaiwala S, et al. (2012) Testosterone supplementation in heart failure: a meta-analysis. Circ Heart Fail 5: 315-321. 